\title{
Inner Ear Disorders: Exploring Possible Links between the Endolymphatic Sac, Gall Bladder and Small Intestine
}

\begin{abstract}
Introduction: In Traditional Chinese Medicine (TCM), the gall-bladder (GB) and small intestine (SI) systems are closely associated with the ear. Acupuncture involving these meridians has been used with success in Meniere's disease where the endolymphatic sac of the inner ear plays a key role. This paper aimed to find out if the endolymphatic sac of the ear shared certain anatomical, physiological and pathological similarities with those of the GB and SI.
\end{abstract}

Methods: A Medline search of the English literature with each of the words "endolymphatic sac", "gall bladder" and "small intestine", was carried out. Relevant English literature detailing the anatomy and physiology of the 3 structures were also reviewed.

Results: The GB, SI \& ES are found to share common anatomical features facilitating the absorption of fluid and electrolytes. In addition, physiological and pathological processes involving allergy, immune-defense, hormonal action and active transport of solutes are involved in all the 3 structures.

Conclusion: If the GB, SI and ES are indeed linked functionally and/or pathologically by one or more of the common themes relating to immunity, the endocrine system as well as fluid and electrolyte homeostasis, plausible medical explanations could possibly be offered for the pathogenesis and treatment of ear disorders as perceived by TCM.

Keywords: Hearing loss; Vertigo; Tinnitus; Meniere's Disease; Acupuncture; Traditional chinese medicine

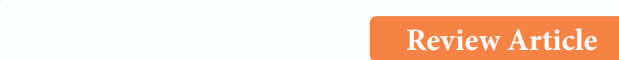

Volume 8 Issue 6 - 2017

Wong-Kein Low ${ }^{1,2,3 *}$, Grad Dip, Sharon Poh ${ }^{2}$ and Mahalakshmi Rangabashyam ${ }^{2}$

${ }^{1}$ Novena ENT-Head Neck Surgery Specialist Centre, Mt

Elizabeth Novena Hospital, Singapore

${ }^{2}$ Department of Otolaryngology, Singapore General Hospital, Singapore

${ }^{3}$ Duke-NUS Graduate Medical School, Singapore

*Corresponding author: Wong-Kein Low, Novena ENT-Head Neck Surgery Specialist Centre, \#04-21/22/34, Mount

Elizabeth Novena Hospital, 38 Irrawaddy Road, Singapore 329563, Singapore, Tel: 65-69330451; Fax: 65-69330547; Email: low.wong.kein@gmail.com

Received: August 09, 2017 | Published: September 18, 2017

\section{Introduction}

Based on observations since the early days, associations between parts of the body and specific zang-fu organ systems have been described in Traditional Chinese Medicine (TCM). The gall-bladder (GB) and small intestine (SI) are two such organ systems which share intimate relation with the ear from the TCM perspective [1]. The meridians of these 2 organ systems are linked by the Sanjiao (SJ) meridian. The SJ system is a zang-fu organ which has no western medicine anatomical equivalent in namesake. Its meridian runs just behind the earlobe and its branches connect with those of the GB and SI meridians. Another organ system which has a close relationship to the ear is the kidney zang organ [2]. According to TCM, the kidney zang organ opens into the ear and kidney disorders can manifest in the ear. Perhaps, this is not surprising to most western doctors as common features between the ear \& kidney are observed in western medicine. For example, medications such as the amino glycosides have toxic side effects, which specifically target the inner ear and kidney. Some congenital malformations of the ear such as the branchio-otorenal syndrome, also affect the kidney.

Unlike the kidney, the GB \& SI have seemingly little if any association to the ear from the western medical view-point. Yet, acupoints belonging to both GB and SI meridians are often used to treat ear symptoms [3]. An ear disorder that stands out is Meniere's disease which acupuncture treatment has been demonstrated to be beneficial [4]. A condition which is still not completely understood, the endolymphatic sac (ES) of the inner ear is believed by most experts to play a key role in the pathogenesis of Meniere's disease [5]. This paper reviews the existing literature with the aim of finding out if the ES shares certain anatomical, physiological and pathological similarities with those of the GB and SI. If so, they could perhaps provide an explanation to the intimate relation of the GB and SI to the ear as defined in TCM.

\section{Methods and Materials}

A Medline search of the English literature with each of the words "endolymphatic sac", "gall bladder" and "small intestine", was carried out. Relevant English literature detailing the anatomy and physiology of the 3 structures were also reviewed.

\section{Results}

\section{Role of allergy and the immune-defence system}

The Churg-Strauss syndrome is a systemic vasculitis that occurs in the setting of asthma or allergic rhinitis with eosinophilia. Rolla et al. [6] reported a 55-year-old man with chronic asthma and rhinosinusitis presenting with acute acalculous cholecystitis and perforation of the ileum. Nishie et al. [7] reported another case 
of 36 year old man again with acute cholecystitis and duodenitis associated with Churg-Strauss syndrome. Occurring in patients with a background of allergy, it may be more than coincidence that the clinical manifestations of this condition focus on the GB and SI. Allergy, particularly food allergy, commonly involves the SI with a prevalence of about $2 \%$. Hagel et al. [8] demonstrated in more than $80 \%$ of patients confirmed to have food allergy, various unspecific non-erosive or erosive mucosal lesions within the small bowel [9]. The GB could also be affected by allergic processes and Reynoso et al. [10] commented that both bile and biliary epithelium have active immunologic roles in both innate and adaptive immune responses. An abnormal gallbladder wall was observed to be significantly associated with anaphylaxis in dogs with acute hypersensitivity reactions [11].

Allergy can affect the ES as well. Mast cell degranulation and eosinophil infiltration had been observed in the inner ear, after antigenic challenge in sensitised guinea pigs [12]. Immunohistochemical localization of Histamine Receptors H(1), $\mathrm{H}(2)$, and $\mathrm{H}(3)$ have also been demonstrated in the ES of rabbits [13]. Mucosa-associated lymphoid tissue (MALT) is a diffuse system of small concentrations of lymphoid tissue found in various submucosal membrane sites of the body, each of which is well situated to encounter antigens passing through the mucosal epithelium. The SI is a major site for MALT activity, with distinct Peyer's patches. Pathogenic microorganisms and other antigens entering the intestinal tract encounter macrophages, dendritic cells, B-lymphocytes, and T-lymphocytes found in Peyer's patches. According to Tomori et al, MALT in the gallbladder is also frequently encountered in clinical practice and may represent a mucosal and morphological immune phenomenon to infections [14]. Primary MALT lymphoma occurring in the gall bladder has been reported, albeit rare [15].

The human ES epithelium was recently found to express a number of mucin molecules, which supports the hypothesis of the sac as the primary immunological tissue structure of the inner ear, equivalent to MALT in other organs. Yan et al. [16] conducted an animal study to determine the immunological relationship between the ES and the Waldeyer ring equivalent, one of the most important effector organs in MALT [17]. The results suggested that the ES is supplied with immunocompetent cells from the Waldeyer ring equivalent and has an ability of co-reacting with the Waldeyer ring equivalent. Hence, the ES appears to act as an immune control organ for the inner ear and an effector site of MALT.

\section{The hormonal factor}

Michelle et al [18] reported a new autosomal recessive syndrome consisting of neonatal diabetes, with hypoplastic pancreas, duodenal/jejunal intestinal atresia and gall bladder hypoplasia/aplasia. Pancreatic immunohistochemistry revealed few scattered chromogranin-A-positive cell clusters but complete absence of insulin, glucagon and somatostatin. Chapell et al. [19] noted that in this syndrome, neonatal diabetes affecting both the GB and the SI can occur without a demonstrable structural pancreatic abnormality, indicating that a deficit in pancreatic function is involved. This particular syndromic linkage between the GB and SI again demonstrates an intimate relationship between these two organs. In this case, it is in the context of a specific dysfunctional hormonal environment.

The ES is also believed to have hormonal-related function. Insulin receptors have been demonstrated in the ES of guinea pigs [20]. In a study by Qvortrup et al. [21] the ES fulfils the morphological criteria of a potential endocrine gland with the chief cells exhibiting all the organelles and characteristics of cells that simultaneously synthesize, secrete, absorb and digest proteins. Specifically, the endolymphatic sac has been found to display somatostatin and/or somatostatin-like immunoreactivity [22]. The secretory granules here were found to be of the same size and appearance as those of intestinal or pancreatic somatostatinproducing cells.

\section{Fluid \& electrolyte balance}

Mucosal epithelial cells of the GB and SI carry out both primary and secondary active transport [23]. Their epithelial cells actively transport $\mathrm{Na}, \mathrm{Cl}$ and $\mathrm{HCO}$ from the lumen across the lateral plasma membrane into the paracellular compartment through the $\mathrm{Na}-$ $\mathrm{K}$ - ATPase and Na-dependent $\mathrm{Cl} / \mathrm{HCO}$ exchanger, causing the concentration of electrolytes in the paracellular space to increase. In the SI, nutrients and other macromolecues are similarly transported by secondary active transport. The absorbed substances are transported across the lateral plasma membrane into the paracellular compartment, causing its concentration in the paracellular space to increase, thus creating an osmotic gradient for water.

Active ion transport systems are also important in the ES. Electrophysiological studies in animals had shown that active transport of $\mathrm{K}^{+}$and $\mathrm{Cl}^{-}$played a role in the ES [24,25]. Using immunohistochemistry, Wackym et al. [26] demonstrated the existence of $\mathrm{Na}^{+}, \mathrm{K}^{+}$-ATPase in the human ES, suggesting active transcellular ion exchanges by the ES epithelium with subsequent passive transcellular and paracellular outflow of water [26]. The expression of $\mathrm{Na}^{+}-\mathrm{K}^{+}-\mathrm{Cl}^{-}$co-transporters in rat ES had been demonstrated, again suggesting the important role active transport plays in endolymphatic fluid homeostasis [27]. Ion channels, ion transporters and ion exchangers are observed in the epithelial cells, especially in the intermediate portion of the ES [28].

The luminal lining of the GB, SI and ES are well-equipped to carry out their absorptive function involved in fluid and electrolyte balance. The mucosa of the GB is elevated into minute rugae with a honeycomb appearance. Its epithelium consists of a single layer of columnar cells with apical microvilli. In sections, projections of the mucosa into the GB lumen resemble villi, with deep mucosal folds [29]. In the same way, the microanatomic organization of the SI is also specialized to increase its surface area. The walls of the gut are thrown into large folds, and its mucosa is similarly organized into villi with microvilli within the plasma membrane. The ES has a sophisticated and highly complex structure of interconnecting tubules, cisterns and crypts [30,31]. The tubules of the sac are oriented primarily transversely to the duct in a complex network, with interconnecting tubules creating a large surface area for exchange of ions, fluid and solutes. There are also distinct folds and villi formations in the epithelial surface of the duct and sac. 


\section{Discussion}

With a history of 2000 to 3000 years, TCM has formed a unique system to diagnose and cure illnesses. The TCM approach treats zang-fu organs as the core of the human body, constituting the centre piece of TCM's systematization of bodily functions. The term zang refers to the five entities considered to be yin in nature, namely the Heart, Liver, Spleen, Lung and Kidney, while fu refers to the six yang organs namely Small Intestine, Large Intestine, Gallbladder, Urinary Bladder, Stomach and Sanjiao. Although these are not considered to be direct equivalents of the anatomical organs, many overlapping functions exist [1]. It is common knowledge that the GB and SI are functionally linked. The transport of bile from the GB to SI is carried out in a co-ordinated fashion, aided by the endocrine system. Besides bile metabolism, our literature review has revealed that the GB \& SI share other common features which in turn, could possibly be thematically linked to the ear via the ES.

The ES is an intriguing part of the inner ear. Unlike the other parts of the inner ear, the functions of the ES are not well defined, not to mention its role in the pathogenesis of inner ear disorders. Besides Meniere's Disease, studies have suggested that it may play a role in the pathogenesis of idiopathic sudden sensori-neural hearing loss and immune-related hearing loss $[32,33]$.

There is clinical and immunologic evidence for a possible role of allergy in Meniere's disease. According to Derebery, the ES sac is the seat of immune reactivity in the inner ear with inhalant and food allergies being linked with Meniere's disease [34]. The exact pathogenesis of food allergy is still not clear, but immediate and delayed types of food allergy have been described. Immediate type of food allergy is mediated by type I hypersensitivity reaction, involving mast cells and food-specific IgE antibodies. In animal studies, Meneire's Disease could be induced by type 1 hypersensitivity which in turn, could be prevented by histamine H(1)-receptor antagonists [35]. Translated into clinical practice, a significant percentage of patients with Meniere's disease and allergy showed improvement in their symptoms of tinnitus and vertigo when receiving specific allergy therapy [34].

An immunologic defense function of the ES is suggested by its association with MALT. In recent years, the belief that the ES is a significant immunological entity of the inner ear was further enhanced by genetic studies which demonstrated increased expression of key elements of both the cellular and humoral innate immune system, including Toll-like receptors 4 and 7 , as well as beta-defensin and lactoferrin [36]. This suggested that not only the ES was capable of antigen recognition and processing for initiation of an immune response, potent molecules directly toxic to invading pathogens were also expressed by the sac epithelium.

The fact that the ES contains cells that demonstrate features of endocrine glands suggest a possible hormonal function [21]. Its association with somatostatin production and insulin receptors perhaps points to a possible involvement in glucose metabolism.

Evidence suggests that a key activity of the ES, GB and SI concerns transfer of fluid and electrolytes with active transport mechanisms likely to be involved. Interestingly, this could possibly be linked to the concept of the "Sanjiao" organ system.
The SJ meridian inter-connects the GB and SI meridians and many of its own acupoints are used to treat ear disorders [3]. The SJ is not considered to be a single self-contained organ, but rather a functional energy system involved in regulating the activities of other organ systems [1]. It is referred to as the "triple burner," as it is essentially involved in metabolism, which is energy-driven. It is closely associated with the spleen function of transformation and transportation of incoming nutrients and the kidney function of domination in water metabolism. Hence, in the context of a possible relationship between the GB, SI and ES, reference can be made to the active transport processes (which requires energy) involved in fluid and electrolyte balance.

It is theoretically possible that the ES, GB and SI are functionally and/or pathologically linked by one or more of the common themes identified in this review; supporting the belief that the ear, GB and SI organ systems are somehow related as observed in TCM practice. It is however, acknowledged that many tissues throughout the body have similarities but to call them 'links' without additional evidence is speculation. Further studies are therefore, warranted to substantiate these possible relationships which perhaps can help to provide plausible medical explanations for the pathogenesis and treatment of ear disorders as perceived by TCM. In addition, exploring inner ear conditions from this perspective may possibly shed new light on disorders like idiopathic sudden sensori-neural hearing loss and Meniere's disease which despite years of research remain poorly understood.

\section{Conclusion}

The GB, SI and ES of the ear share a number of common features relating to the immune and endocrine systems as well as to fluid and electrolyte homeostasis. If these 3 organ systems are indeed functionally and/or pathologically linked by one or more of these common themes, plausible medical explanations can possibly be offered for the pathogenesis and treatment of ear disorders as perceived by TCM.

\section{Acknowledgement}

The editorial assistance from Ms Lhu Hui Ling is greatly appreciated.

\section{Conflicts of Interest}

Author there is no conflict of Interest.

\section{References}

1. ZuoYF (2002) Basic Theory of Traditional Chinese Medicine. Publishing House of Shanghai University of Traditional Chinese Medicine, China

2. Low WK (2010) Acupuncture in the treatment of ear disorders. In: Fiedler D \& Krause R (Eds.), Deafness, hearing loss and the auditory system. Nova Science Publishers, New York, USA, pp. 373.

3. Liu GW (2006) Clinical Acupuncture and Moxibustion. (2nd edn), Huaxia Publishing House Beijing, China

4. Long AF, Xing M, Morgan K, Brettle A (2011) Exploring the Evidence Base for Acupuncture in the Treatment of Ménière's Syndrome-A Systematic Review. Evid Based Complement Alternat Med 2011 429102. 
5. Wetmore SJ (2008) Endolymphatic sac surgery for Ménière's disease: long-term results after primary and revision surgery. Arch Otolaryngol Head Neck Surg 134(11): 1144-1148.

6. Rolla G, Tartaglia N, Motta M, Ferrero N, Bergia R, et al. (2007) Warning nonrespiratory symptoms in asthma: catastrophic abdominal involvement in a case of Churg-Strauss syndrome. Ann Allergy Asthma Immunol 98(6): 595-597.

7. Nishie M, Tomiyama M, Kamijo M, Kannari K, Tanosaki M, et al. (2003) Acute cholecystitis and duodenitis associated with ChurgStrauss syndrome. Hepatogastroenterology 50(52): 998-1002.

8. Ahmed T, Fuchs GJ (1997) Gastrointestinal allergy to food: a review. J Diarrhoeal Dis Res 15(4): 211-223.

9. Hagel AF, de Rossi TM, Zopf Y, Lindner AS, Dauth W, et al. (2012) Small-bowel capsule endoscopy in patients with gastrointestinal food allergy. Allergy 67(2): 286-292.

10. Reynoso-Paz S, Coppel RL, Mackay IR, Bass NM, Ansari AA, et al. (1999) The immunobiology of bile and biliary epithelium. Hepatology 30(2): 351-357.

11. Quantz JE, Miles MS, Reed A, White GA (2009) Elevation of alanine transaminase and gallbladder wall abnormalities as biomarkers of anaphylaxis in canine hypersensitivity patients. J Vet Emerg Crit Care (San Antonio) 19(6): 536-544.

12. Uno K, Miyamura K, Kanzaki Y, Fukuda H, Masuyama K, et al. (1992) Type I allergy in the inner ear of the guinea pig. Ann Otol Rhinol Laryngol Suppl 157: 78-81.

13. Dagli M, Goksu N, Eryilmaz A, Mocan Kuzey G, Bayazit Y, et al. (2008) Expression of histamine receptors $(H(1), H(2)$, and $H(3))$ in the rabbit endolymphatic sac: an immunohistochemical study. Am J Otolaryngol 29(1): 20-23.

14. Tomori H, Nagahama M, Miyazato H, Shiraishi M, Muto Y, et al. (1999) Mucosa-associated lymphoid tissue (MALT) of the gallbladder: a clinicopathological correlation. Int Surg 84(2): 144-150.

15. Honda M, Furuta Y, Naoe H, Sasaki Y (2017) Primary mucosaassociated lymphoid tissue (MALT) lymphoma of the gallbladder and review of the literature. BMJ Case pii: 2017-220161.

16. Møller MN, Kirkeby S, Cayé-Thomasen P (2017) Innate immune defense in the inner ear - mucines are expressed by the human endolymphatic sac. J Anat 230(2): 297-302.

17. Yan Z, Wang JB, Gong SS, Huang X (2003) Cell proliferation in the endolymphatic sac in situ after the rat Waldeyer ring equivalent immunostimulation. Laryngoscope 113(9): 1609-1614.

18. Mitchell J, Punthakee Z, Lo B, Bernard C, Chong K, et al. (2004) Neonatal diabetes, with hypoplastic pancreas, intestinal atresia and gall bladder hypoplasia: search for the aetiology of a new autosomal recessive syndrome. Diabetologia 47(12): 2160-2167.

19. Chappell L, Gorman S, Campbell F, Ellard S, Rice G, et al. (2008) A further example of a distinctive autosomal recessive syndrome comprising neonatal diabetes mellitus, intestinal atresias and gall bladder agenesis. Am J Med Genet A 146A(13): 1713-1717.

20. Knight LC, Saeed SR, Hradek GT, Schindler RA (1995) Insulin receptors on the endolymphatic sac: an autoradiographic study. Laryngoscope 105(6): 635-638.
21. Qvortrup K, Rostgaard J, Holstein-Rathlou NH, Bretlau P (1999) The endolymphatic sac, a potential endocrine gland? Acta Otolaryngol 119(2): 194-199.

22. Arnold W, Altermatt HJ, Arnold R, Gebbers JO, Laissue J, et al. (1986) Somatostatin (somatostatinlike) immunoreactive cells in the human inner ear. Arch Otolaryngol Head Neck Surg 112(9): 934-937.

23. John E (2010) Hall Guyton and Hall Textbook of Medical Physiology. $\left(12^{\text {th }}\right.$ edn), Saunders, Elsevier, USA, p. 1-20.

24. Morgenstern C, Miyamoto H, Arnold W, Vosteen KH (1982) Functional and morphological findings of endolymphatic sac. Acta Otolaryngol 93(1-6): 187-194.

25. Amano H, Orsulakova A, Morgenstern C (1983) Intracellular and extracellular ion content of the endolymphatic sac. Arch Otorhinolaryngol 237(3): 273-277.

26. Wackym PA, Glasscock ME, Linthicum FH Jr, Friberg U, Rask-Andersen $\mathrm{H}$, et al. (1988) Immunohistochemical localization of $\mathrm{Na}^{+}, \mathrm{K}^{+-}$ATPase in the human endolymphatic sac. Archives of Oto-rhino-laryngology 245(4): 221-223.

27. Nishimura M, Kakigi A, Takeda T, Takeda S, Doi K (2009) Expression of aquaporins, vasopressin type 2 receptor, and $\mathrm{Na}^{+} \mathrm{K}^{+}-\mathrm{Cl}$ cotransporters in the rat endolymphatic sac. Acta Otolaryngol 129(8): 812-818.

28. Mori N, Miyashita T, Inamoto R, Matsubara A, Mori T, et al. (2017) Ion transport its regulation in the endolymphatic sac: suggestions for clinical aspects of Meniere's disease. Eur Arch Otorhinolaryngol 274(4): 1813-1820

29. Anthony Mescher (2009) Junqueira's Basic Histology: Text and Atlas. $\left(12^{\text {th }}\right.$ edn), McGraw-Hill Medical, USA.

30. Takumida M, Bagger-Sjöbäck D, Rask-Andersen H, Harada Y (1989) Epithelial Cell Surface Morphology in the Endolymphatic Sac: A Scanning Electron Microscopic Study in the Mouse. Auris Nasus Larynx 16(1): 1-12

31. Lo WW, Daniels DL, Chakeres DW, Linthicum FH Jr, Ulmer JL, et al. (1997) The endolymphatic duct and sac. AJNR Am J Neuroradiol 18(5): 881-887.

32. Naganawa S, Koshikawa T, Fukatsu H, Ishigaki T, Nakashima T, et al (2002) Contrast-enhanced MR imaging of the endolymphatic sac in patients with sudden hearing loss. Eur Radiol 12(5): 1121-1126.

33. Satoh H, Firestein GS, Billings PB, Harris JP, Keithley EM (2003) Proinflammatory cytokine expression in the endolymphatic sac during inner ear inflammation. J Assoc Res Otolaryngol 4(2): 139 147.

34. Derebery MJ (1997) The role of allergy in Meniere's disease. Otolaryngol Clin North Am 30(6): 1007-1016.

35. Egami N, Kakigi A, Takeda T, Takeda S, Nishioka R, et al. (2014) Type 1 allergy-induced endolymphatic hydrops and the suppressive effect of H1-receptor antagonist (olopatadine hydrochloride). Otol Neurotol 35(3): e104-e109.

36. Møller MN, Kirkeby S, Vikeså J, Nielsen FC, Cayé-Thomasen P (2015) Gene expression demonstrates an immunological capacity of the human endolymphatic sac. Laryngoscope 125(8): E269-E275. 